\title{
CÔNG THỨC NÀO CHO BÀI PHÁT BIỂU THUYẾT PHỤC CỦA CỬU TỔNG THỐNG MỸ BARACK OBAMA TẠI HÀ NỘI?
}

\author{
Nguyễn Thị Hằng Nga* \\ Khoa Tiếng Anh, Truòng Đại họ Ngoại ngũ, ĐHQGHN, \\ Phạm Văn Đồng, Cầu Giấy, Hà Nội, Việt Nam \\ Nhận bài ngày 05 tháng 04 năm 2017 \\ Chỉnh sửa ngày 02 tháng 01 năm 2018; Chấp nhận đăng ngày 19 tháng 01 năm 2018
}

Tóm tắt: Chuyến thăm chính thức kéo dài ba ngày của tổng thống Mỹ tại Việt Nam cuối tháng 5 năm 2016 nhận được nhiều bàn luận của người dân cũng như của báo chí, đặc biệt là báo chí mạng. Nhiều bài viết về sự kiện này hoặc khen quá mức, hoặc phủ nhận những đóng góp của chuyến thăm quan trọng này. Chúng tôi đã tiến hành nghiên cứu trường hợp đối với bài diễn văn này, tiếp cận từ nhiều chiều kích bao gồm diễn thuyết, tâm lí học và quốc tế học để tìm ra công thức cho tính thuyết phục của bài diễn văn: nguời nói có quyền lục gì, nguời nói tác động tới cảm xúc người nghe nhu thế nào và nguời nói đưa ra lí lẽ ra sao. Kết quả nghiên cứu sẽ có có ý nghĩa không chỉ về nghệ thuật diễn thuyết đối với diễn giả mà còn về khả năng tiếp nhận thông tin của người nghe trong một thế giới thông tin đa chiều, không giới hạn như hiện nay. Sự ngưỡng mộ hay phê phán nên bớt cảm tính, trào lưu và tăng tính khách quan, khoa học.

Tù khóa: diễn thuyết, tính thuyết phục, diễn văn, tư duy phản biện

\section{Mở đầu}

\subsection{Li do và muc đích}

Chuyến thăm chính thức kéo dài ba ngày của tổng thống Mỹ tại Việt Nam cuối tháng 5/2016 nhận được vô số sự bàn luận của người dân cũng như của báo chí, đặc biệt là báo chí mạng. Rất nhiều bài viết bàn luận về sự kiện này hoặc khen quá mức, hoặc phủ nhận những đóng góp của chuyến thăm quan trọng này. Chúng tôi tiến hành nghiên cứu bài diễn văn để đưa ra đánh giá khách quan, không cảm tính, không phụ thuộc quá nhiều vào truyền thông mạng và tâm lí đám đông, đồng thời mong muốn tìm ra công thức cho những thành công đó để chúng ta cùng học hỏi và ứng dụng.

\subsection{Phuơng pháp và đối tương}

Chúng tôi triển khai nghiên cứu các yếu tố hiển ngôn và hàm ngôn của văn bản trên nền kiến thức từ nhiều chiều kích có liên quan mật

\footnotetext{
*ĐT.: 84-987888976

Email: hangngakhtnhn@yahoo.com
}

thiết nhằm trả lời câu hỏi: Tính thuyết phục của bài diễn văn Tổng thống Obama trình bày tại Hà Nội là do các yếu tố nào tạo nên?

\section{Nội dung}

Triết gia cổ đại Aristotle mô tả 3 yếu tố làm nên sự thuyết phục của một bài diễn thuyết là Người nói, Người nghe và Lí lẽ /Ethos, Pathos, Logos (Krista C. McCormack, 2014).

Ethos đề cập đến uy tín của người nói được cảm nhận bởi người nghe. Nếu người ta tin cậy bạn với tư cách diễn giả, bạn sẽ dễ dàng hơn nhiều trong việc làm cho họ tin điều bạn nói. Nếu họ không thích, không tin bạn, không dễ gì thuyết phục họ vì họ luôn luôn có một dòng hải lưu ngầm của thái độ hoài nghi.

Pathos có nghĩa là tạo được cảm xúc nơi người nghe, khơi dậy sự quan tâm của họ.

Logos có nghĩa là lôgíc. Thông tin, lập luận phải làm cho khán giả thấy được tính hợp lí. Bằng chứng, chứng minh cho các lập luận cũng rất cần thiết, có thể bao gồm số liệu, hình ảnh và kinh nghiệm. 
Chúng tôi sẽ phân tích bài phát biểu của Tổng thống Obama dựa trên 3 yếu tố này: 2 yếu tố Người nói và Người nghe chủ yếu từ góc độ diễn thuyết và tâm lí; Li lẽ chủ yếu từ góc độ Quan hệ quốc tế.

\subsection{Người nói (Ethos)}

Theo giáo sư về lãnh đạo học Kinicki (2009), trong các tương tác liên nhân, lãnh đạo, cha mẹ và giáo viên... đa số nhằm mục đích tạo ảnh hưởng/social influence đến nhân viên, con cái và học trò. Nếu thiếu đi quyền lực/social power trong những mối quan hệ kiểu này thì sẽ ảnh hưởng đến tính hiệu quả của tổ chức, gia đình và lớp học. Quyền lực xã hội/social power được định nghĩa là $k h a ̉$ năng thu xếp nguồn lục con nguời, nguồn lực thông tin và nguồn lục vật chất để thực hiện một nhiệm vụ nào đó.

Có 5 yếu tố tạo nên 5 loại quyền lực xã hội, mà nhờ các quyền lực này một cá nhân nào đó có thể gây ảnh hưởng đến các cá nhân khác. Tổng thống Obama đang sở hữu quyền lực chức vụ/legitimate power: là tổng thống của một cường quốc thế giới về kinh tế và chính trị. Yếu tố vị trí và thẩm quyền thường giúp người sở hữu giành được sự tuân thủ của người nghe. Không những thế, tiểu sử của Obama - ông trở thành vị tổng thống da màu đầu tiên của Mỹ, ông tạo ấn tượng với thế giới bởi cuộc sống gia đình êm ấm hạnh phúc, ông giữ phong thái bình dân, thân thiện - cũng ít nhiều tạo ra quyền lực yêu mến/referent power, giúp ông dễ tạo ảnh hưởng đến khán giả.

\subsection{Ngườ nghe (Pathos)}

Theo chuyên gia về diễn thuyết Devito (2009), khán giả của diễn thuyết bao gồm khán giả trực tiếp /Immediate Audience và khán giả gián tiếp/Secondary Audience. Khán giả trực tiếp bao gồm những người nghe diễn giả trình bày trực tiếp hoặc qua các phương tiện nghe, nhìn. Khán giả gián tiếp bao gồm tất cả những người đọc nội dung bài phát biểu, hoặc đọc, nghe về bài phát biểu qua khán giả trực tiếp hoặc một người đọc hoặc nghe về bài phát biểu đó một cách gián tiếp. Chúng tôi nghiên cứu bài phát biểu này trong cả hai vai trực tiếp (nghe video tiếng Anh trên Youtube) và gián tiếp (đọc bài phát biểu toàn văn tiếng Anh trên obamawhitehouse.archives.gov và đọc bài phát biểu toàn văn tiếng Việt trên trang mạng chính thống VOV của Việt Nam).

Để dẫn dắt cảm xúc của người nghe, định hướng sự quan tâm của họ và thôi thúc hành động, diễn văn của các chính trị gia Mỹ đã có khuôn mẫu, được nghiên cứu và đào tạo bài bản và khoa học và là vũ khí tư tưởng hữu hiệu. Mục đích của các bài phát biểu là nhằm thay đổi (tăng cường, làm yếu hoặc thay đổi) thái độ, niềm tin, giá trị và thúc đẩy hành động của khán giả (Devito, 2009)

Giống như các bài diễn văn chính trị mà chúng tôi đã nghiên cứu, đặc biệt là trường hợp diễn văn của Hillary Clinton giúp Obama tranh cử, các diễn giả thường áp dụng các kĩ thuật giọng nói và kĩ thuật dụng ngũ̃ như lặp từ, tương phản, qui tắc bộ 3 , tạo sự thân thiện...(N.T.H. Nga, 2014; N.T.H. Nga, N. N. Toàn, 2016). Bài diễn văn của Obama áp dụng đúng và đủ các thủ pháp đó. Trong nghiên cứu này, chúng tôi tập trung phân tích kĩ thuật $S u ̛$ i dụng lời lẽ tạo sụ thân thiện, vì Obama ưu tiên sử dụng kĩ thuật này một cách nổi trội. Trong diễn văn, diễn giả thường áp dụng cách này để tạo mối quan hệ gần gũi, thân thiết và cuốn hút khán giả, tạo ra sự lưu thông về cảm xúc và sau đó là sự lưu thông về tư tưởng, sự hợp tác về hành động. Kĩ thuật bao gồm: ca ngợi, chia sẻ riêng tư, quan tâm, đồng nhất và hứa hẹn.

\subsubsection{Khen ngơi}

Tổng thống hào phóng khen ngợi đất nước gồm lịch sử, địa lí, khoa học, giáo dục, văn hóa, kinh tế, y tế, ngoại giao, ẩm thực, con người...

- Có rất nhiều các bạn trẻ tù khắp moi noi trên đất nước Việt Nam đã có mặt tại đây, ho đại diện cho sư năng động, tài năng và niềm hy vong của Việt Nam.

- Người cha lập quốc của nuớc Mỹ Thomas 
Jefferson tìm cách mua lúa để trồng trong các trang trại của minh, ông đã tìm đến lúa của Việt Nam, loại lúa gạo mà theo ông là trắng nhất, ngon nhất và năng suất nhất.

- Tôi đã ... được ăn nhũng món ăn Việt Nam rất ngon (outstanding)

- Tôi đến đây với tất cả sụ tôn trọng dành cho lịch sư lâu đời của Việt Nam

- Thế giới rất coi trọng sản phẩm lụa và các bức tranh của Việt Nam. Văn Miếu của các bạn đã truờng tồn cùng thời gian nhu môt bằng chứng rõ ràng về sự hiếu học của nguò̀i Việt.

- Cũng giống nhu cây tre, tinh thần bất khuất của các bạn được thể hiện rõ qua câu tho thần của danh tuớng Lý Thuờng Kiệt: "Sông núi nuớc Nam vua Nam ở, Rành rành định phận tại sách trời”.

Nếu những lời ca ngợi đó được nói bởi một người Việt Nam thì hiệu ứng có như vậy hay không? Có lẽ không, thậm chí có thể bị chỉ trích là con hát mẹ khen hay, gặm nhấm quá khứ, gặm nhấm chiến thắng. Có lẽ, vì nếp nghĩ Bụt chùa nhà không thiêng, và vì khi đó, Việt Nam là khái niệm cha chung không ai $k h o ́ c$, đối lập với phạm trù cái tôi của mỗi các nhân. Kết quả có thể là không một cá nhân nào quan tâm.

Nhưng khi một người nước ngoài khen ngợi, chúng ta lập tức thu nhận Việt Nam vào cái ta của mình trong thế đối lập với người nước ngoài - một cái ta khác. Họ khen Việt Nam chính là đang tung hô cái tôi của mỗi cá nhân chúng ta. Thông thường, chúng ta luôn muốn tiếp nhận thông điệp loại này một cách vô thức.

Chúng ta cảm tình với những lời khen đó vì thần tượng nước Mỹ, tổng thống Mỹ, vì tư duy cảm tính thiên vị Yêu nhau yêu cả đường đi lối về hay vì thích sự vỗ về cái tôi của mỗi chúng ta?

Hơn thế nữa, rất nhiều bài viết về sự kiện Obama đến Hà Nội có chút hào phóng khi ca ngợi người diễn thuyết có tâm tình đặc biệt dành cho Việt Nam khi nói về Việt Nam thông kinh thuộc sử như vậy. Sự khen ngợi có lúc hơi quá ưu ái, nhưng điều này có thể hiểu là một hình thức đối ngoại văn hóa của khách đối với nước chủ nhà để cả hai bên đều hài lòng: chủ cảm nhận được sự tôn trọng của khách, ngược lại khách nhận được sự chào đón nồng hậu.

\subsubsection{Riêng tur}

Những câu chuyện riêng tư của những nhân vật nổi tiếng luôn là mối quan tâm của đại đa số dân chúng. Người ta chỉ chia sẻ sự riêng tư trong một mối quan hệ gần gũi, tin tưởng. Vì vậy, khi Obama nói với khán giả nhưng câu chuyện cá nhân dung dị đời thường, là ông đã dỡ bỏ những ngăn trở về địa vị, về văn hóa để đến gần người dân Việt Nam hơn, thể hiện sự tin tưởng họ và được họ tin tưởng. Những thông điệp đậm chất cá nhân giữa ông và khán giả dường như xóa mờ sự cách trở về địa vị tổng thống Mỹ với người dân Việt Nam.

Trong chuyến thăm này, tình cảm chân thành của người dân Việt Nam đã chạm đến trái tim tôi. Có rất nhiều nguời đã xuống đường vẫy tay và tuơ i cuời với tôi để thể hiện tình hũu nghị giũa nhân dân hai nước.

Tối qua, tôi đã đi thăm khu phố cổ Hà Nội và được ăn nhũng món ăn Việt Nam rất ngon. Tôi đã ăn bún chả và uống bia Hà Nội. Tôi phải nói thật rằng, đường phố của các bạn rất nhộn nhịp và cả đời mình tôi chưa tùng thấy nhiều xe máy đến vậy. Tôi chura thư tìm cách sang đường nhung có lẽ khi tôi quay trở lại, các bạn sẽ giúp tôi làm điều này.

\subsubsection{Quan tâm}

Bài diễn văn là một hỗn hợp hoàn hảo của chính luận quốc gia, văn hóa hàn lâm và văn hóa đại chúng với những tên tuổi đặc trưng thể hiện sự am hiểu về Việt Nam như Lý Thuờng Kiệt, Hai Bà Trung, Phan Chu Trinh, Nguyễn Du, Văn Cao, Đại tướng Võ Nguyên Giáp, Trịnh Công Son, GS Ngô Bảo Châu... những biểu tượng hồn Việt tinh tế như Truyện Kiều, Cây tre, Sông Hồng, trống đồng Đông Sơn, lụa, tranh..., và những địa danh chứa đựng niềm tự hào của người dân Việt: Văn Miếu, 36 phố phường Hà Nội, Hội An, cố đô Huế, Vịnh Hạ Long, Hang Sơn Đoòng...

Sự am hiểu này là cách diễn tả thực tế nhất việc vị tổng thống Mỹ quan tâm đến một quốc 
gia khác như thế nào. Sự quan tâm là điều kiện không thể thiếu để một lãnh đạo tạo ảnh hưởng đến những người khác vì ảnh hưởng không phải luôn luôn đến từ vị trí, ảnh hưởng đến từ sự quan tâm. (N.T.H. Nga, 2017).

\subsection{4. Đồng nhất (với khán giả)}

Sự đồng nhất thể hiện ngay khi ông bắt đầu cũng như kết thúc diễn văn bằng ngôn ngữ của người Việt. Hơn nữa, lời chào được lặp đi lặp lại có thể là chuyện thường tình trong các bài diễn văn kiểu Mỹ, nhưng đối với người Việt, nó mang đến thông điệp về sự ân cần và lòng nhiệt thành.

Xin chào! Xin chào Việt Nam

Xin cám ơn! Xin cám ơn rất nhiều!

Mỹ là một cường quốc thế giới, trong khi Việt Nam chỉ là một quốc gia đang phát triển. Nhưng trong đối thoại, vị tổng thống luôn thể hiện sự bình đẳng, nổi bật nhất là cách sử dụng ngôi xưng hô thứ nhất "Chúng ta":

cuộc chiến giũ̃a hai nuớc chúng ta.

là đã gắn chúng ta lại với nhau

lôi chúng ta vào xung dọt

ơ cả hai nuoóc chúng ta, thay đổi

mối quan hệ giữa hai quốc gia chúng ta cũng

chúng ta tìm kiếm ngưò̀ mất tich

sinh viên chúng ta cùng học với nhau, các vị học giả của chúng ta cùng nghiên cúu với nhau.

có rất nhiều người Việt Nam thậm trí còn trẻ hơn tôi rất nhiều.

Có những đoạn diễn văn kết hợp 3 kĩ thuật đồng nhất, khen ngợi với riêng tư, tăng mạnh hiệu ứng kết thân với khán giả.

Giống nhur 2 con gái tôi...

Nhiều người Việt Nam còn trẻ hơn tôi...

\subsubsection{Húa hẹn}

Lời hứa hẹn về một tương lai tươi sáng có lẽ luôn là thứ dễ nghe và dễ có cảm xúc tích cực, đặc biệt khi người hứa hẹn này thường được khán giả coi là một trong những nhân vật quyền lực của thế giới. Người nghe cũng ít nhiều gia tăng hi vọng về tương lai. Obama hứa hẹn về rất nhiều lĩnh vực trọng yếu gồm ngoại giao, kinh tế (đặc biệt là TPP), con người, bình đẳng giới, giáo dục, giảng dạy tiếng Anh, đào tạo công nghệ, đảm bảo an ninh quốc gia.

Mỹ vui mùng khi đã giúp đõ Việt Nam tham gia hơn nũ̃a về gìn giữ hòa bình của Liên hợp quốc.

Tôi ủng hộ mạh mẽ TPP, bởi vì bản thân tôi sẽ giúp cho Việt Nam xuất khẩu nhiều sản phẩm hàng hóa đến Mỹ. Điều này sẽ giúp cho Việt Nam không phải phu thuộc thuoong mại với quốc gia nào duy nhất mà mở rộng thị truoòng của mình nhu với Hoa Kỳ.

Chúng tôi sát cánh cùng đối tác tư do hàng hải, tụ do hàng không, tụ do thuoong maii.

Mùa thu năm nay Đại học Fullbright sẽ đi vào hoạt động.

Đội hòa bình sẽ đến Việt Nam.

Chuyên gia về lãnh đạo học Simon Sinek (2015) cho rằng khi con người nhìn thấy dấu hiệu hoàn thành mục tiêu, chất dẫn truyền thần kinh dopamine được sản sinh trong não khiến chúng ta tập trung hơn, tỉnh táo hơn và hài lòng hơn. Điều này có thể giải thích cho việc người nghe hứng thú với nội dung phát biểu của tổng thống vì ông đang vẽ ra tương lai với nhiều mục tiêu hợp mong muốn của người dân Việt Nam.

\subsection{Li lẽ (Logos)}

Bàn về tính logic trong diễn văn của Obama có lẽ là một việc không mang lại kết quả bất ngờ. Obama khen ngợi có dẫn chứng, nhấn mạnh sự tương đồng có dẫn chứng và thể hiện sự quan tâm có dẫn chứng: những dẫn chứng đắt giá chạm đến trái tim khán giả (như chúng tôi đã phân tích ở phần trước).

Ở phần này, chúng tôi đi sâu mô tả và phân tích một kĩ thuật đắc nhân tâm ngầm ẩn trong bài phát biểu: Kĩ thuật Foot in the door. Với kĩ thuật này, người diễn thuyết chỉ đề nghị một đề nghị rất nhỏ, hợp lí với khán giả. Bởi vì trước khi người nghe đưa ra quyết định về những thay đổi lớn, họ đòi hỏi nhiều lí lẽ hơn, nhiều bằng chứng hơn, do đó việc thuyết phục trở nên vô cùng thách thức với diễn giả. Trái lại, những yêu cầu nhỏ thì dễ thuyết phục hơn. Trên thực tế, con người thay đổi dần dần trong một quãng thời gian. Ví dụ, nếu bạn muốn thay đổi người nghiện rượu thì nên bắt đầu bằng việc mời họ đến dự một buổi 
nói chuyện của hội cai rượu, sẽ dễ dàng hơn yêu cầu họ bỏ rượu suốt đời. Yêu cầu thay đổi tận gốc thái độ và hành vi là điều dễ khiến cho diễn giả thất bại vì ngay lập tức vì người nghe sẽ loại bỏ bạn, bịt tai trước cả những lí lẽ logic và tuyệt vời nhất. Một khi khán giả đã đồng ý với yêu cầu nhỏ, giờ đến lúc đưa ra yêu cầu mà bạn thực sự muốn. Người ta có xu hướng tiếp thu và thỏa hiệp với những yêu cầu lớn sau khi đã thỏa hiệp với yêu cầu nhỏ tương tự (Devito, 2009).

Chỉ chiếm phần rất nhỏ và thoáng qua trong bài phát biểu, nhưng mục tiêu chính trị của chuyến thăm cũng như bài phát biểu nằm ở từ khóa nhân quyền/human right. Thuật ngữ này chỉ xuất hiện 3 lần trong suốt bài phát biểu dài 4195 từ tiếng Anh. Điều này biểu lộ sự thận trọng của diễn giả khi bàn về nhân quyền. Phạm trù này gắn với quan điểm và thể chế chính trị nên từ xưa đến nay luôn nhạy cảm và có nhiều sự khác biệt giữa Mỹ và Việt Nam đúng như Obama thừa nhận "Quan hệ của chúng ta là giải quyết sự khác biệt giữa hai chính quyền về nhân quyền". Thế nhưng, Tổng thống Mỹ dường như khá thoải mái khi lặp lại 26 lần trong đoạn diễn văn gồm 526 từ tiếng Anh với mật độ dày đặc, và nhấn mạnh ý này bằng lớp từ ngữ bình dân như tư tin của dân chúng, tư do hội họp, tư do ngôn luận và biểu tình... (chúng tôi gạch chân các diễn đạt đó trong đoạn trích dưới đây) khiến một việc chính sự bỗng trở thành những mẩu chuyện phiếm, không mang màu sắc chính trị mà người dân ai cũng có thể bàn bạc. Đoạn này diễn giả trích dẫn Hiến pháp của Việt Nam, sau đó diễn giải và đề cao ý nghĩa của quyền tự do công dân. Chúng tôi sử dụng bản tiếng Anh và tự chuyển dịch để đáp ứng tối đa quá trình mô tả.

They're written into the Vietnamese constitution, which states that "citizens have the (1) right to freedom of speech and freedom of the press, and have the right of access to information, the right to assembly, the right to association, and the right to demonstrate."

When there is freedom of expression and freedom of speech, and when people can share ideas and access the Internet and social media without restriction, that fuels the innovation economies need to thrive. ... because somebody had a new idea. It was different. And they were able to share it. When there's freedom of the press -- when journalists and bloggers are able to shine a light on injustice or abuse -- that holds officials accountable and builds public confidence that the system works. When candidates can run for office and campaign freely, and voters can choose their own leaders in free and fair elections, it makes the countries more stable, because citizens know that their voices count and that peaceful change is possible. And it brings new people into the system.

When there is freedom of religion, it not only allows people to fully express the love and compassion that are at the heart of all great religions, but it allows faith groups to serve their communities through schools and hospitals, and care for the poor and the vulnerable. And when there is freedom of assembly -- when citizens are free to organize in civil society -- then countries can better address challenges that government sometimes cannot solve by itself. So it is my view that upholding these rights is not a threat to stability, but actually reinforces stability and is the foundation of progress.

After all, it was a yearning for these rights that inspired people around the world, including Vietnam, to throw off colonialism. And I believe that upholding these rights is the (26) fullest expression of the independence that so many cherish, including here, in a nation that proclaims itself to be "of the People, by the People and for the People."

Diễn đạt tiếng Việt tương ứng với 26 cụm từ tiếng Anh
1. Quyền tự do ngôn luận
2. Quyền tự do báo chí
3. Quyền tiếp cận thông tin
4. Quyền họi hop 
5. Quyền lập hội

6. Quyền biểu tình

7. Tư do diễn đạt

8. Tư do ngôn luận

9. Chia sẻ ý kiến

10. Tiếp cận Internet và mạng xã hội không bị hạ ché

11. Chia sẻ môt ý tuớng mói

12. Tư do báo chí

13. Các nhà báo và bloggers tỏa sáng

14. Xây dựng sự tự tin của dân chúng

15. Úng viên vận động tư do

16. Ngườ tham gia bầu củ tụ do lưa chon lãnh đạo trong các cuộc bầu củ tụ do và công bằng

17. Tiếng nói của công dân có giá trị

18. Sự thay đổi một cách hòa bình là có thể

19. Tu do tín nguỡng

20. Bày tỏ hết tình yêu thurong

21. Lập họi nhóm

22. Công dân tự do lậ ra các tổ chức

23. Duy trì nhũng quyền này

24. Khao khát nhũng quyền này

25. Duy trì nhũng quyền này

26. Thể hiện đầy đủ quyền tư do

Nếu nhân quyền là một phạm trù vĩ mô của hai nhà nước thì những nội dung mà Obama nêu trên thực sự mang lại cảm giác về tính vi mô vì nó diễn đạt những vấn đề của mỗi cá nhân trong xã hội: chỉ là sử dụng Facebook chia sẻ ý kiến cá nhân, là việc người dân tự do chọn người mình thích, tự do nhóm họp, tự do nói lên ý kiến... Theo thuyết Foot in the door, những gì là vi mô, giản dị liên quan đến người dân sẽ được người dân dễ dàng đón nhận mà không cần quá nhiều lí lẽ và biện luận (Devito, 2009)

Ngoài ra, Tổng thống cũng biện luận khéo léo làm nổi bật những lợi ích của những quyền trên mà tuyệt nhiên không nói đến những tiêu cực đã hiển lộ và đang tiềm ẩn.

"Ngày nào, chúng tôi cũng nhận được phê bình, tôi và Chính phủ, nhung nhũng lời chỉ trích, tranh luận cởi mở giúp chúng ta nhìn nhận sụ chưa hoàn hảo. Việc mọi nguoòi có quyền đưa ra lời phê phán thì chính là điều giúp xã hội tiến bộ hơn.

... Giá trị Hoa Kỳ mà chúng tôi nói là giá trị tổng quát được nêu trong Hiến pháp Việt Nam nhu nguoòi dân có quyền tư do ngôn luận, lập họi. Đây là nhũng điều đã được nêu trong Hiến pháp Việt Nam.

... Chúng ta tiếp cận Internet vì thúc đẩy sáng tạo mà nền kinh tế cần có để phát triển, nhu Facebook. Đó là noi bắt đầu các ý tưởng.

... Trong đất nước tư do, người dân sẽ lưa chọn lãnh đạo tốt nhất cho họ, mọi người có quyền bày tỏ sự nhân ái... Các quyền bình đẳng người dân Việt Nam sẽ mang đến nền tảng cho sự thịnh vượng và lợi ich cho tất cả người dân Việt Nam."

Thành ngữ tiếng Anh có câu "A coin has two sides/ Mọi đồng xu đều có hai mặt”. Ý nghĩa của câu thành ngữ này không xa lạ với Tổng thống, với nhiều người dân Việt Nam, nhưng không phải là tất cả khán giả Việt Nam nghe trực tiếp và xem truyền hình. Chúng tôi hơi e ngại cách lập luận thiên vị này có thể dẫn đến sự hiểu biết một chiều của khán giả, có thể khiến chính họ khó tiếp cận với bản chất của những gì đang diễn ra.

Tuy nhiên, xét về kĩ thuật lấy lòng khán giả, Obama đã rất thành công khi khiến công chúng an tâm, hào hứng với những thứ mà chính quyền địa phương thận trọng vốn cho là "quả táo đẹp nhưng độc" như Facebook.

Trong một đoạn diễn văn khác, Obama tin tưởng và hi vọng về sự hợp tác mới, có tính lịch sử giữa hai nước. Những cam kết mà nhân dân thế giới nói chung và nhân dân Việt Nam nói riêng mong đợi cuối cùng cũng được chính người lãnh đạo quyền lực của thế giới khẳng định:

"Chúng tôi đã chứng tỏ hòa bình có thể tốt hơn chiến tranh như thế nào.

Chúng tôi đã chứng minh sư tiến bộ và giá trị của con người sẽ được thúc đẩy tốt nhất bằng sư hợp tác và không xung đột. Đó là nhũng gì Việt Nam và Mỹ chưng minh cho thế giới.

.... . Việt Nam là một quốc gia độc lập, chủ quyền, và không có quốc gia nào có thể áp đặt hoặc quyết định số phận của các bạn. Bây giờ, Hoa Kỳ có sụ quan tâm ở đây." 
Đó là một phần lí do tại sao thính giả ngưỡng mộ, nể phục và trân trọng Obama. Vì ông đã mang đến cho họ một cảm giác đảm bảo (trong nhiệm kì của tổng thống) về một nền hòa bình và chủ quyền cho Việt Nam, một đất nước đã từng có với Mỹ mối quan hệ đau thương và nhiều tổn thất.

Bên cạnh sự yên tâm nêu trên, thông qua những hiển ngôn trong bài phát biểu, chúng tôi đồng thời đã tiến hành khai thác hàm ngôn để nhận biết hiển ngôn ở các tầng khác nhau. Sau đây là giả định của chúng tôi về một vài hiển ngôn trên cơ sở nhận biết hữu hạn bối cảnh hiện nay của thế giới.

Thư nhất là sự hiện diện của chiến tranh ủy nhiệm (CTUN). Theo Thiếu tướng, PGS. TS. Trần Minh Sơn, Viện trưởng Viện 70, Tổng cục II (2014), CTUN là loại hình chiến tranh được tiến hành bằng cách thông qua lực lượng của một hoặc nhiều nước khác, hay các tác nhân phi nhà nước - còn gọi là chiến tranh qua tay người khác. Loại hình chiến tranh này đang được một số nước, đứng đầu là Mỹ coi trọng sử dụng để can dự vào các cuộc xung đột nhằm đạt mục tiêu chiến lược mà không sử dụng lực lượng trực tiếp tham chiến.

Thư hai, nhà báo Toàn Thắng (2016) cũng đăng tin: "Phó Thủ tướng Thổ Nhĩ Kỳ Numan Kurtulmus cũng đồng nhận định với Tổng thống Syria Assad rằng, cuộc nội chiến Syria hiện nay đã trở thành "cuộc chiến ủy nhiệm" giữa Mỹ và Nga,... Nga và Mỹ đang hậu thuẫn cho các bên tham gia cuộc xung đột kéo dài hơn 5 năm qua ở đất nước Syria".

Thú ba, tác giả Bắc Hà (2015) viết: "Là quốc gia có vị trí địa lý quan trọng trong khu vực, Việt Nam là cầu nối trên đất liền giữa phần lớn nhất của lục địa Á, Âu với khu vực Đông Nam Á, đa sắc tộc, giàu tài nguyên; Hoàng $\mathrm{Sa}$, Trường $\mathrm{Sa}$ nằm trên tuyến hành lang đường biển thuận tiện, với 50\% khối lượng hàng hóa luân chuyển của thế giới đi qua vùng biển này. Cùng với tài nguyên phong phú, dân số khá lớn... những điều kiện này đã khiến Việt Nam trở thành một trong những quốc gia có vị trí địa chính trị quan trọng bậc nhất trong khu vực và trên thế giới. Hiện nay, nhiều cường quốc xem khả năng kiểm soát Biển Đông là "lợi ích cốt lõi” của mình. Chính vì vậy mà Biển Đông đã trở thành một trong những “điểm nóng” lớn nhất về lợi ích giữa nhiều nước lớn. Trong thế kỷ 20, nhiều quốc gia phát triển đã sớm nhận thấy vị trí địa chính trị quan trọng của Việt Nam. Từ những quốc gia xa xôi trên thế giới, thậm chí bên kia đại dương đã "vươn" tới Việt Nam, mong muốn sớm thiết lập quan hệ thân thiện. Song chính vì vị trí địa chính trị đó mà dân tộc Việt Nam đã thường xuyên phải đương đầu với các cuộc chiến tranh xâm lược..."

Một trong những lí lẽ Tổng thống đã nêu khi phát biểu bao gồm: không xung đột, không áp đặt, Việt Nam là một quốc gia độc lập, chu quyền, tụ quyết định số phận, Hoa Kỳ có sư quan tâm ở đây, chúng tôi quan tâm đến sụ thành công của Việt Nam (Now, the United States has an interest here. We have an interest in Vietnam's success). Trong câu tiếng Anh này, interest có thể được hiểu là $s u ̛$. quan tâm hoặc lơi ích.

Với vai trò khán giả của bài phát biểu, chúng ta không nên băn khoăn một cách cảm tính mọi thiện chí của các vị khách quí đến từ Hoa Kỳ. Tuy nhiên, nội hàm của từ, ngữ đôi lúc rất khó hiểu nếu chúng không được gắn với bối cảnh cụ thể hoặc bị gắn nhầm bối cảnh. Nói một cách khách quan, khi khán giả hoặc các nhà nghiên cứu biết thêm nhiều bối cảnh khác liên quan đến hiển ngôn trong bài phát biểu, thì hàm ngôn cũng có thể nhiều hơn và đa dạng hơn.

Trong phần cuối diễn văn, Tổng thống nỗ lực truyền đạt thông điệp chính trị về sự hợp tác mới giữa hai nước. Trong nghệ thuật diễn thuyết, phần đầu diễn giả thường tập trung vào mục đích xây dựng quan hệ với người nghe, và dần dần chiếm lĩnh tình cảm và chinh phục thái độ của họ trong phần giữa diễn văn. Hai 
bước này thực ra cũng chỉ là nền cho phần quan trọng nhất phía cuối là kêu gọi hành động. Và vẫn bằng kĩ thuật Foot in the door, vẫn là những yêu cầu nhẹ nhàng và dễ dàng với khán giả:

Số phận trong tay của các bạn. Đây là thời điểm của các bạn. Và khi các bạn theo đuổi tuoong lai các bạn muốn, tôi muốn các bạn biết rằng Hoa Kỳ sẽ luôn sã̃n sàng bên cạh các bạn với tu cách là đối tác, là bạn bè. (Your destiny is in your hands. This is your moment. And as you pursue the future that you want, I want you to know that the United States of America will be right there with you as your partner and as your friend.)

Khán giả Việt Nam có lẽ “được lời như cởi tấm lòng” khi vị Tổng thống phương Tây lẩy Kiều để tiếp nối dẫn chứng và cũng là kết thúc bài diễn thuyết.

Rằng trăm năm cũng tù đây

Của tin gọi một chút này làm ghi.

\section{Kết luận}

Tóm lại, bài diễn văn của Tổng thống Mỹ tại Hà Nội được đón nhận với sự ngưỡng mộ là do khai thác tốt 3 nhân tố người nói, người nghe và lí lẽ. Qua nghiên cứu các bài diễn thuyết của lãnh đạo các quốc gia như Barack Obama Hillary Clinton, Tshering Tobgay,... chúng tôi nhận thấy rằng các cử chỉ, hành động của lãnh đạo dễ khiến công chúng gắn với các thông điệp chính trị, nên họ rất chú trọng và thường có chiến lược thể hiện. Do đó, từ nụ cười, cách bắt tay, gật đầu, cho cá ăn đến diễn thuyết chính trị đều có thể nằm trong các tình huống ngoại giao mà các chính trị gia Mỹ đã được đào tạo bài bản.

Nghiên cứu của chúng tôi phân tích và mô tả bài diễn văn từ nhiều chiều để hiểu về nó sâu sắc hơn. Kết quả này có thể vẫn là chưa đầy đủ. Khi có thêm dữ liệu và công cụ, chúng tôi hi vọng sẽ tiếp tục nghiên cứu để khai thác được nhiều thông tin hơn nữa.

Chúng tôi mong muốn kết quả nghiên cứu sẽ có đóng góp thực tế và có ý nghĩa không chỉ về nghệ thuật diễn thuyết mà còn về khả năng tiếp nhận thông tin trong một thế giới thông tin đa chiều, không giới hạn như hiện nay. Sau khi những cơn sóng của sự ái mộ Obama lắng xuống, chúng ta cần thời gian để suy nghĩ và kiểm chứng thêm những thông điệp ngọt ngào mà bài diễn văn mang lại. Và nhất định sự kiểm chứng đó phải dựa trên thông tin xác thực và đầy đủ với những hành động tương ứng.

\section{Tài liệu tham khảo}

\section{Tiếng Việt}

Bắc Hà (2015). Vị trí địa chính trị của Việt Nam với đường lối quốc phòng. Báo Quân Đội Nhân Dân online, http://www.qdnd.vn/chong-dien-bien-hoabinh/vi-tri-dia-chinh-tri-cua-viet-nam-voi-duongloi-quoc-phong-25833, truy cập lúc 16.00 ngày $1 / 1 / 2018$.

Nguyễn Thị Hằng Nga (2014). Sử dụng ngôn ngữ hiệu quả trong diễn thuyết: Nghiên cứu trường hợp.

Ngôn ngũ và Đời sống, số 11, trang 72-77.

Nguyễn Thị Hằng Nga và nhóm nghiên cứu (2015). Diễn thuyết bằng thuật dụng ngôn hiệu quả. Báo cáo Hội thảo khoa học quốc tế: "Ngôn ngũ học Việt Nam 30 năm đổi mói và phát triển", Hà Nội, ngày 23 tháng 8 năm 2015.

Nguyễn Thị Hằng Nga, Nguyễn Ngọc Toàn (2016). Nghiên cứu trường hợp về mô hình giọng nói hiệu quả trong diễn thuyết. Tạp chi Khoa học ĐHQGHN: Nghiên cúu Nước ngoài, 32(1), trang 17-27.

Nguyễn Thị Hằng Nga, Nguyễn Ngọc Toàn (2017). "Giao thoa" Lãnh đạo học và Dạy học trong việc sử dụng ngôn ngữ giao tiếp. Kỉ yếu Hội thảo Ngũ học toàn quốc lần thứ 20 "Ngôn ngữ ở Việt Nam: Hội nhập và phát triển", Tp. Qui Nhơn, ngày 16 tháng 9 năm 2017, tr. 727-737.

Simon Sinek (2015). Lãnh đạo luôn ăn sau cùng. Hà Nội: NXB Lao động.

Trần Minh Sơn (2014). Chiến tranh ủy nhiệm và giải pháp phòng, chống. Tạp chí Quốc phòng toàn dân, http://tapchiqptd.vn/vi/nghien-cuu-trao-doi/chientranh-uy-nhiem-va-giai-phap-phong-chong/6500. html, truy cập lúc 8.00 ngày $1 / 1 / 2018$.

Toàn Thắng (2016). Thế chiến 3 , chiến tranh NgaMỹ bùng phát từ xung đột Syria? Báo Dân Tri, $\quad$ http://dantri.com.vn/the-gioi/the-chien-3chien-tranh-nga-my-bung-phat-tu-xung-dotsyria-20161015111032556.htm, truy cập lúc 10.00 ngày $1 / 1 / 2018$.

VOV (2016). Toàn văn phát biểu Tổng thống Obama tại Trung tâm Hội nghị Quốc gia. Báo điện tử của Đài Tiếng nói Việt Nam/VOV, http://vov.vn/chinhtri/toan-van-phat-bieu-tong-thong-obama-tai-trungtam-hoi-nghi-quoc-gia-513962.vov, truy cập lúc $11: 30$ ngày $6 / 6 / 2016$. 


\section{Tiếng Anh}

Joseph A. Devito (2009). The Essential elements of Public Speaking. USA: Pearson Education, Inc.

Kinicki, Kreitner (2009). Organization behavior. New York: Mc Graw-Hill.

Yukl, G., Gordon, A., Taber, T. (2002). A hierarchical taxonomy of leadership behavior: integrating a half century of behavior research. Journal of Leadership and Organizational Studies, 9, 5-32.
Krista C. McCormack (2014). Ethos, Pathos, and Logos: The Benefits of Aristotelian Rhetoric in the Courtroom. Jurisprudence Review, 7, 131-155.

The White House (2016). Remarks by President Obama in Address to the People of Vietnam.

https://www.whitehouse.gov/the-pressoffice/2016/05/24/remarks-president-obamaaddress-people-vietnam, Truy cập lúc 10:30 ngày 6/6/2016.

\title{
WHAT FORMULA FOR PERSUASIVENESS OF SPEECH BY FORMER PRESIDENT BARACK OBAMA IN HANOI?
}

\author{
Nguyen Thi Hang Nga \\ Faculty of English, VNU University of Languages and International Studies, \\ Pham Van Dong, Cau Giay, Hanoi, Vietnam
}

\begin{abstract}
The three-day official visit of the US president to Vietnam on May 2016 has received countless discussions of local people as well as articles on multimedia, many of which are online and either sound excessively complimentary, or deny potential contributions of this major political event. We have conducted a case study from perspectives of Public Speaking, Psychology and International Studies to discover a formula for persuasiveness of the speech: What powers the speaker has, how the speaker influences the audience's emotion and how the speaker argues. In the world of multimedia and multidimensional information, our research would result in some practice-oriented strategies for both rhetoric science and media literacy. Admiration or criticism should be less emotional, trendy and crowd-driven. It should be more objective and scientific instead.
\end{abstract}

Keywords: public speaking, persuasiveness, rhetoric science, media literacy 